\title{
THE MANY FACES OF ORAL-FACIAL-DIGITAL SYNDROME
}

\author{
Sukarova-Angelovska E ${ }^{1, *}$, Angelkova N ${ }^{2}$, Palcevska-Kocevska S ${ }^{3}$, Kocova $\mathrm{M}^{1}$
}

*Corresponding Author: Assistant Profesor Elena Sukarova-Angelovska, Pediatric Clinic, Faculty of Medicine, Vodnjanska 17, 1000 Skopje, Republic of Macedonia; Tel.: +389-70-358582; Fax: +389-2243301; E-mail: ESukarova@doctor.com

\section{ABSTRACT}

The oral-facial-digital (OFD) syndrome is a heterogeneous group of abnormalities that share anomalies of the oral cavity, face and digits of hands and feet. On the basis of other anomalies of brain, kidneys, limbs, eyes and other organs, at least 13 subgroups have been described. We here describe four unrelated patients with this syndrome, who have the typical facial, oral and digital anomalies and also anomalies of other organs and systems. Facial features, digital malformations, as well as the existence of additional malformations all of which can be classified into different subgroups. The report points out the difficulty in delineation of the subtypes of OFD syndrome because of the overlapping features between OFD subgroups.

Key words: Oral-facial-digital (OFD) syndrome; Oral cleft; Polydactyly; Ciliopathy; Genetic and clinical heterogeneity

\section{INTRODUCTION}

The first description of the oral-facial-digital (OFD) syndrome was published six decades ago [1]. Since then, significant heterogeneity and variability

Department of Endocrinology and Genetics, Pediatric Clinic, Skopje, Republic of Macedonia

2 Department of Neurology, Pediatric Clinic, Skopje, Republic of Macedonia

3 Department of Neonatology, Pediatric Clinic, Skopje, Republic of Macedonia have been reported $[2,3]$. The spectrum of anomalies includes variations in findings in the oral cavity: cleft palate/uvula, multiple frenulae, tongue nodules and hamartomas; in the face: hypertelorism, cleft lip, alar hypoplasia, bulbous nose and digital findings; and in hands and feet: pre/postaxial polydactyly, syndactyly, and brachydactyly. The severity of the any of these features is not correlated with that of other features or with the degree of mental retardation. Anomalies of brain, eye, heart, kidney, genitalia have been described, of which some are specifically connected with specific subtypes of the syndrome. So far, 13 subtypes have been described according to the mode of inheritance and the involvement of the other organs and systems (eye, brain, tibia, skeletal changes, and presence of millia) [4]. However, classification into the subtypes is not always easy or clear, and additional subgroups have been proposed [5-7]. Only OFD syndrome type 1, which represents only a small portion of all OFD syndromes, has an established genetic defect so far $[8,9]$. This subtype is characterized by an X-linked dominant mode of inheritance with mutations in the OFD1 gene. With 23 coding regions, this gene has a crucial role in the biology of primary cilia, however, point mutations and deletions, mostly on exons 3, 8, 9 and 13, are described. It has been shown that tongue hamartomas are more consistent with the mutation of the OFD1 gene, than with other subtypes of OFD where no mutation of this gene was found [10].

We here describe four unrelated patients with different types of OFD syndrome. This report again 
points out the difficulty in prompt delineation and proper diagnosis of the OFD syndromes. Overlapping features between subtypes of OFD syndrome in each patient are discussed in details.

\section{CLINICAL MATERIAL}

Patient 1. An 18-month-old Albanian boy was the firstborn of unrelated, healthy young parents with an unremarkable family history. The pregnancy was uneventful and the delivery was full term and normal, birth weight 3600 grams. Psychomotor development was poor with a generalized hypotonia and attenuated primitive reflexes. Constant eye movement was noticed early in infancy. Their second child was also a boy and was healthy at the age of 4 months.

On examination, the patient was $81 \mathrm{~cm}$ long and weighted $10 \mathrm{~kg}$. He had a notch at the upper lip, highly arched palate, multiple frenulae, small teeth, multiple nodules on the tongue and an infralingual hamartoma. His facial appearance was characterized by frontal bossing, telecanthus, hypertelorism, deepset eyes, and mild micrognathia. He had permanent rotatory nystagmus and ceaseless eyelid movement. Both hands showed minor postaxial polydactyly, with no involvement of skeletal structures. X-Ray examination of the hands showed slight widening of the terminal phalanges of both thumbs and dysplastic, broad and short intermediate phalanges of all fingers. The nails were short and broad. X-Ray examination of the feet showed varus deformity, bifid terminal phalanges of the hallux and hypoplastic
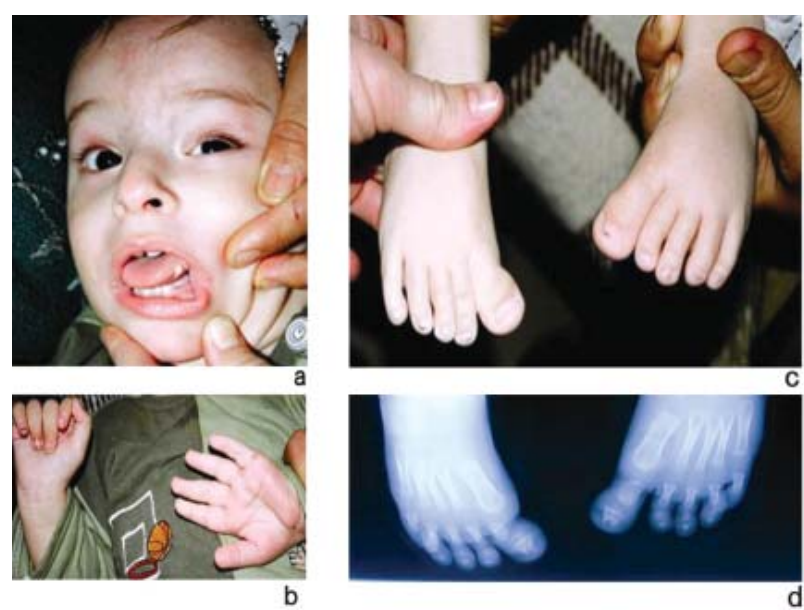

Figure 1. Patient 1: (a) notched upper lip, small teeth, tongue nodules and hamartoma; (b) broad first toes bilaterally; (c) minor skeletal changes of the feet. phalanges of the toes. The length of the limbs was proportional to the body size (Figure 1).

No malformation was detected in the cardiovascular and urinary systems. The boy showed severe delay in motor and mental development. At 18 months he could not sit or stand on his own and had generalized hypotonia with outbursts of unmotivated stereotypic movement. A computed tomography (CT) scan of the brain was not performed. Fundoscopy and karyotype were both normal.

Patient 2. A 4-year old girl was the sixth child of unrelated parents of Muslim origin. There is no history of anomalies in the family. She was born after a normal pregnancy and delivery, with birth weight $3100 \mathrm{~g}$ and body length $49 \mathrm{~cm}$. Motor delay was noticed when she was 4 months old. At examination she showed motor developmental delay, poor coordination, speech delay (was only able to pronounce a few words). The first four girls have normal intelligence and were without any malformation. The fifth child was a boy and had moderate mental retardation with seizures as a consequence of a perinatal trauma, but no apparent malformation.

The patient had hypertelorism, narrow palpebral fissures, high arched palate, multiple frenulae, broad nasal root, and low-set posteriorly rotated ears with protruded lobules. Her neck was short and she had mesoaxial hexodactyly on both hands, the extra digit originating from the fourth finger. X-ray examination showed $Y$ shaped third metacarpal on the right hand, the extra digit being hypoplastic. On the left hand she had only five metacarpal bones, while the hypoplastic phalanges of the extra finger originated from the root of the fourth finger. There were preaxial polydactyly of both halluces. The first metatarsal bones were broad bilaterally (Figure 2). A CT scan revealed mild hydrocephaly, vermis hypoplasia and widening of the fourth chamber. Ultrasonographic evaluation of the kidneys and heart was normal. Karyotype was also normal.

Patient 3. A 3-month-old girl of Albanian ethnicity was the second child of healthy, unrelated parents (mother was 38 and father 39 years old, respectively), and she was referred to hospital for intermittent tachypnoea. The older, 14-year-old sister, was severely mentally retarded. The mother had four miscarriages before the birth of the patient who, after an uneventful pregnancy, was delivered at term by cesarean section because of her breech position, birth weight $3300 \mathrm{~g}$ and length $50 \mathrm{~cm}$. 

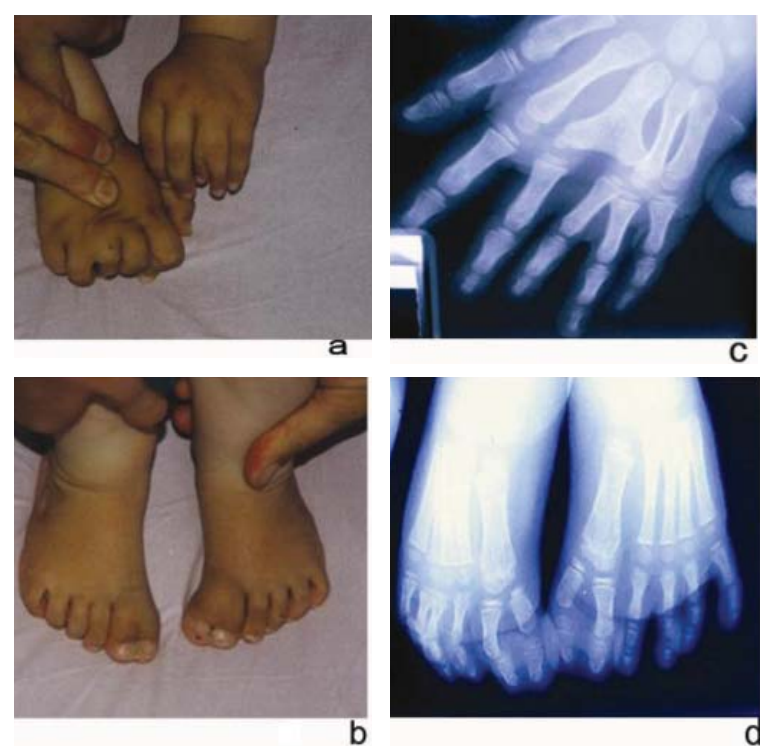

Figure 2. Patient 2: (a) mesoaxial polysyndactyly of the hands; (b) duplicated halluces with duplicated nails; (c) Roentgenograms showing forked third metacarpal on the right hand and broad metatarsal bones on the feet.

Postnatal period was normal. On examination postaxial polysyndactyly of the left hand and duplicated first toes bilaterally were noted. She had mild facial dysmorphism including hypertelorism, telecanthus, long palpebral fissures, and a beaked nose (Figure 3). The tongue was lobulated and the ears were low-set. The eyes showed intermittent episodes of "sinking" without permanent nystagmus. Umbilical hernia 2' $1 \mathrm{~cm}$ and diastasis of abdominal muscles were present. An X-ray revealed duplication of phalanges of the extra finger originating from the root of the fifth metacarpal bone. There was duplication of proximal and distal phalanges on the left toe, and duplication of the distal phalange of the right toe. Both first metatarsal bones were broadened. Ultrasonography of the brain, heart and kidneys gave normal results. Karyotype was also normal.

The sister had no features of OFD syndrome and the reason for her developmental delay was unsolved. The mother was healthy and ultrasonography of her kidneys was normal.

Patient 4. The newborn with phenotypically ambiguous genitalia, was referred to the hospital because of respiratory distress syndrome and the presence of multiple anomalies. The family history was unremarkable. The parents were young and not related, of Gipsy origin, and had a healthy girl previously. The second pregnancy was complicated by
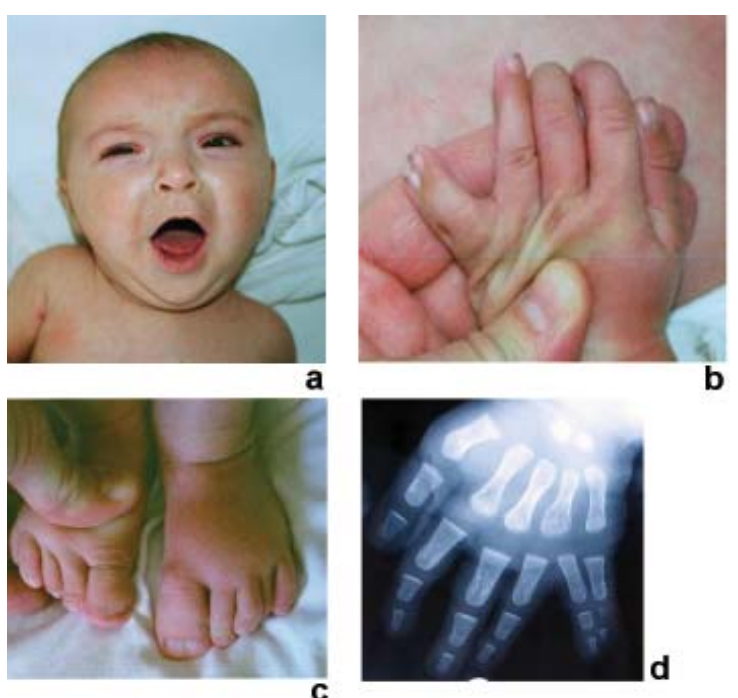

Figure 3. Patient 3: (a) facial features of the infant; (b) postaxial polydactyly of the left hand; (c) mesoaxial poly-syndactyly on the feet

olygohydramnios and caudal presentation of the fetus, and was ended by cesarean section at the 34th gestational week because of placental abruption, birth weight was $1750 \mathrm{~g}$ and length $43 \mathrm{~cm}$, Apgar score was $4 / 5 / 7$ at $1 / 5 / 10$ minutes, respectively. After the primary resuscitation, the baby was referred to our clinic for further evaluation.

The following dysmorphic features were found: wide forehead, proptosis, telecanthus, antimongoloid slanted eyes; broad and short nose with bulbous tip, anteverted nares and hypoplastic nasal wings. The philtrum was long and smooth with notch of the upper lip. The tongue was lobed, with hamartoma on the surface and the median cleft along the whole length. There was a pseudocleft of the hard palate with widening of the alveolar ridges. The ears were large, low-set and poorly shaped with preauricular tags on the right side. The neck was short with loose skin. Mesomelic shortening of all limbs was present, i.e., the forearm was shorter than the upper arm by $2 \mathrm{~cm}$, and lower leg shorter than the upper leg by $2.5 \mathrm{~cm}$. There was mesoaxial hexadactyly of both feet with syndactyly of the third, fourth and fifth toes on the right and of the second and third toes on the left. There was postaxial polydactyly of both hands. The nails on the hands and feet were hypoplastic. The genitalia showed ambiguity, a bifid scrotum and clitoriform penis (stage 2 on the Prader scale of viriliza- 

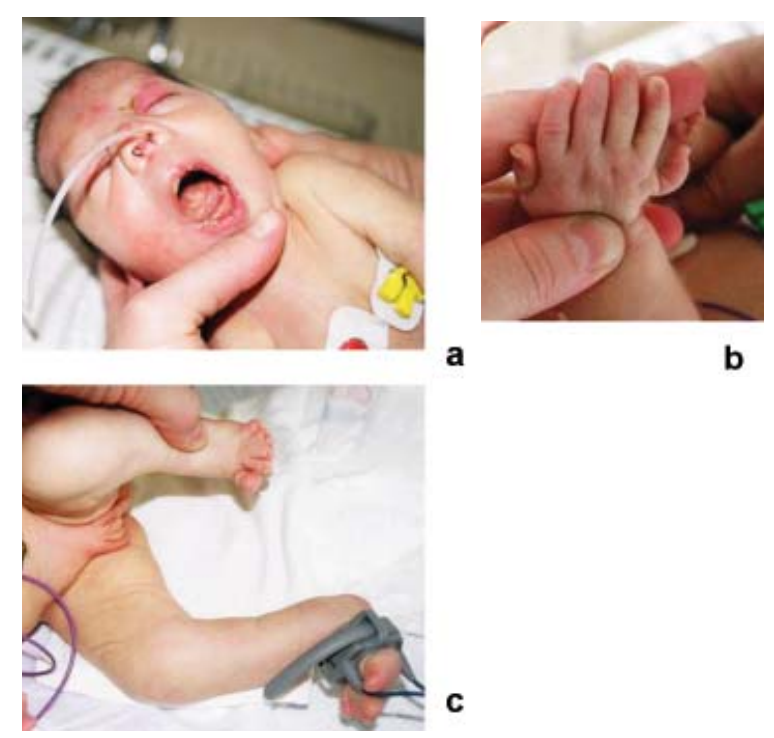

Figure 4. Patient 4: (a) facial dysmorphism included hypertelorism, telecantus, lobed tongue; (b) details of the left hand; (c) both feet.

tion); testes were not palpable (Figure 4). The karyotype was $46, \mathrm{XY}$. The TORCH screen was normal.

The X-rays showed normal length of the ribs, mesomelic shortening of the tibiae and fibulae, polydactyly of hands and feet including metacarpal/tarsal bones and phalanges. Ultrasonography revealed partial atrioventricular canal, and a hypoplastic left kidney.

Two weeks after birth, the child died of cardiorespiratory insufficiency following an apnoeic episode. Autopsy revealed bilaterally lobulated lungs, partial hypoplasia of the intrahepatic and extrahepatic biliary ducts. The testes were histologically normal, and were located at the upper part of the inguinal channel. The structure of the brain was normal.

\section{DISCUSSION}

The group of OFD syndromes presents mainly with malformations of the face, oral cavity and lower parts of the limbs (hands and feet). Other organs may also be affected, including kidney, brain, heart, eye, genitalia. Thus, the number of subgroups keeps growing, with the new published cases. Considering the broad spectrum of anomalies of various organs, it has been proposed that OFD syndromes belong to the group of ciliopathies [4].

There is no definite consent about the classification of OFD. Modes for classification of OFD syn- dromes were proposed by different authors, mostly based on the additional malformations and survival: oral-facial-skeletal syndromes [11]; orocardiodigital variant [12]; CAVE, cerebroacrovisceral early lethal [13]. Fenton and Watt-Smith [2] proposed only two types of OFD (autosomal recessive and X-linked), based on the inheritance pattern. However, inheritance cannot always be determined. The spectrum of appearance and extensivity of the features could be variable, thus it is difficult to delineate between the described subgroups. Overlapping of the features between groups is common; therefore classification of a specific patient is sometimes difficult. Appearance of a new feature added to the syndrome is also common.

There are some point markers for delineation between subgroups of OFD and related syndromes $[3,14]$; however, diagnostic doubt can be seen in many reports [15-17]. Phenotypic variations were also present in our patients.

Patient 1 had many clinical characteristics of OFDII, according to the generally accepted classification [3]. Minor polydactyly of the hands and feet together with the oral findings (notch of the lip, tongue nodules and hamartoma) point to OFDV, but our patient's mental retardation was much more severe than that described for this subtype. A previously undescribed feature in this patient was preaxial polydactyly of the feet. Similar minor limb manifestation was described by Levy et al. [18], clarified as Mohr syndrome. Abnormal eye movements and rotatory nystagmus can distinguish type III from the other types. However, limb anomalies are presented only by postaxial polydactyly of the feet in this type as reported so far. On the other hand, rotatory nystagmus has been described in some cases of OFDII. Therefore, patient 1 fits into this group (Table 1). The degree of polydactyly is not always in concordance with the degree of mental retardation (as in our patient); however, it is in concordance with cerebral changes. Unfortunately, KTM was not performed in our patient.

The phenotypic appearance of patient 2 is suggestive of an OFDVI because of the presence of Y shaped metacarpals, central polydactyly of the feet, cerebellar anomalies and specific facial appearance with hypertelorism. Some authors $[16,19]$ found central polydactyly with forked metacarpal in OFDII but others $[20,21]$ consider forked metacarpal 
Table 1. Clinical features of our four patients. (Feature present in a patient $[+]$; feature absent in a patient $[-]$; not known [?]; feature not yet presented [/].)

\begin{tabular}{|c|c|c|c|c|c|}
\hline Clinical Features & Affected Organ & Patient 1 & Patient 2 & Patient 3 & Patient 4 \\
\hline \multirow{4}{*}{ Oral } & cleft lip & {$[+]$} & {$[-]$} & {$[-]$} & {$[+]$} \\
& frenula & {$[+]$} & {$[+]$} & {$[+]$} & {$[+]$} \\
& high/cleft palate & {$[+]$} & {$[+]$} & {$[+]$} & {$[+]$} \\
& tongue nodules/lobules & {$[+]$} & {$[-]$} & {$[+]$} & {$[+]$} \\
& hamartoma & {$[+]$} & {$[-]$} & {$[-]$} & {$[+]$} \\
Facial & small/abnormal teeth & {$[+]$} & {$[+]$} & {$[/]$} & {[]} \\
\hline \multirow{4}{*}{ Hand } & hypertelorism & {$[+]$} & {$[+]$} & {$[+]$} & {$[-]$} \\
& bulbous/bifid nose & {$[-]$} & {$[+]$} & {$[+]$} & {$[+]$} \\
& low-set ears & {$[-]$} & {$[+]$} & {$[+]$} & {$[+]$} \\
& abnormal eye movement & {$[+]$} & {$[-]$} & {$[+]$} & {$[?]$} \\
\hline \multirow{4}{*}{ Foot } & postaxial plydactyly & {$[+]$} & {$[-]$} & {$[+]$} & {$[+]$} \\
& preaxial polydactyly & {$[+]$} & {$[-]$} & {$[-]$} & {$[-]$} \\
& mesoaxial polydactyly & {$[-]$} & {$[+]$} & {$[-]$} & {$[-]$} \\
\hline CNS & syndactyly & {$[-]$} & {$[+]$} & {$[+]$} & {$[-]$} \\
\hline Heart & postaxial plydactyly & {$[-]$} & {$[-]$} & {$[-]$} & {$[-]$} \\
\hline Kidney & preaxial polydactyly & {$[+]$} & {$[+]$} & {$[+]$} & {$[-]$} \\
\hline Subtype & mesoaxial polydactyly & {$[-]$} & {$[-]$} & {$[-]$} & {$[+]$} \\
\hline
\end{tabular}

a cardinal feature of OFDVI. Central nervous system (CNS) malformations, rarely present in other types of OFD syndromes, are most consistent with OFDI and OFDVI [22]. Although a female, this patient is unlikely to have OFDI because of the lack of skin millia and specific family history: the mother did not have any oral or kidney anomalies; the four sisters of the patient were also normal.

The features of patient 3 may be consistent with most of the OFD syndromes. The family history: mentally retarded sister and miscarriages (possible aborted male fetuses) may point to the diagnosis of $\mathrm{X}$-linked dominant OFDI syndrome. However, the older sister did not have the features of OFD syndrome, and the mother at the age of 38 years did not have renal cysts. Also, the baby did not have pseudocleft of the upper lip or millia. Tachypnoea that was not permanent, but frequent event can point to the diagnosis of OFDVI, in which tachypnoea together with postaxial polydactyly of fingers and bifid hallux have been described. Other syndromes such as Joubert syndrome [23] also have episodes of tachypnoea, however, they were described to have only postaxial polydactyly of the hands and feet, which was not present in our patient.
The complex and apparently lethal condition of patient 4 represents a form with the main features of OFD syndromes: lobed tongue with medial cleft and hamartoma, postaxial polysyndactyly of hands and feet. In addition, the newborn had mesomelic limb shortening, so it could be OFDIV. In the differential diagnosis of this case other syndromes were considered. The diagnosis of Majewski syndrome was excluded because of the absence of short ribs. The typical breathing pattern for Joubert syndrome (tachypnoea) was absent, although the baby had episodes of apnea. The diagnosis of Hall-Pallister syndrome [24] was excluded because of the absence of the hamartoma of the brain and anal anomalies present in this condition. We cannot fully exclude the diagnosis of the lethal form of Smith-Lemli-Opitz syndrome [25], since there are many overlapping features, i.e., unlobulated lungs, ambiguous gentialia, etc. The phenotypic similarity of these two syndromes was pointed by Verloes et al. [26].

The subgroup OFDIV seems to be very heterogeneous [27], ranging from minor orofacial and skeletal changes, to major malformations of many organs. For example, cardiac malformations have been described in several types of OFD syndrome 
Table 2. Some patients from the literature describing oral-facial-digital syndrome and multisystemic involvement. (Feature present in a patient [+]; feature absent in a patient [-]; not described by author [?].)

\begin{tabular}{|c|c|c|c|c|c|c|c|c|c|c|c|c|}
\hline $\begin{array}{c}\text { Clinical } \\
\text { Features }\end{array}$ & Affected Organ & Patient 4 & [29] & [30] & [17] & [28] & [20] & [5] & [34] & [31] & [32] & [33] \\
\hline Oral & $\begin{array}{c}\text { cleft lip } \\
\text { frenula } \\
\text { high/cleft palate } \\
\text { lobed/cleft tongue } \\
\text { hamartoma }\end{array}$ & $\begin{array}{l}+] \\
{[+]} \\
{[+]} \\
{[+]} \\
{[+]}\end{array}$ & $\begin{array}{l}?] \\
{[?]} \\
{[+]} \\
{[+]} \\
{[?]}\end{array}$ & $\begin{array}{l}{[+]} \\
{[?]} \\
{[+]} \\
{[+]} \\
{[?]}\end{array}$ & $\begin{array}{l}{[?]} \\
{[?]} \\
{[+]} \\
{[+]} \\
{[?]}\end{array}$ & $\begin{array}{l}+] \\
{[?]} \\
{[+]} \\
{[+]} \\
{[?]}\end{array}$ & $\begin{array}{l}+] \\
{[+]} \\
{[+]} \\
{[+]} \\
{[+]}\end{array}$ & $\begin{array}{l}+] \\
{[+]} \\
{[+]} \\
{[+]}\end{array}$ & $\begin{array}{l}{[+]} \\
{[?]} \\
{[+]} \\
{[+]} \\
{[?]}\end{array}$ & $\begin{array}{l}{[-]} \\
{[+]} \\
{[+]} \\
{[+]} \\
{[+]}\end{array}$ & $\begin{array}{l}{[-]} \\
{[?]} \\
{[+]} \\
{[+]} \\
{[?]}\end{array}$ & $\begin{array}{l}{[+]} \\
{[?]} \\
{[+]} \\
{[+]} \\
{[?]}\end{array}$ \\
\hline Facial & $\begin{array}{c}\text { hypertelorism } \\
\text { proptosis } \\
\text { bulbous/bifid nose } \\
\text { low-set ears } \\
\text { micrognathia }\end{array}$ & $\begin{array}{l}{[+]} \\
{[+]} \\
{[+]} \\
{[+]} \\
{[+]}\end{array}$ & $\begin{array}{l}{[?]} \\
{[+]} \\
{[+]} \\
{[+]} \\
{[+]}\end{array}$ & $\begin{array}{l}{[+]} \\
{[?]} \\
{[?]} \\
{[?]} \\
{[+]}\end{array}$ & $\begin{array}{c}{[+]} \\
\text { unilateral } \\
{[+]} \\
{[?]} \\
{[+]}\end{array}$ & $\begin{array}{l}{[?]} \\
{[?]} \\
{[?]} \\
{[?]} \\
{[+]}\end{array}$ & $\begin{array}{l}{[+]} \\
{[?]} \\
{[+]} \\
{[?]} \\
{[+]}\end{array}$ & $\begin{array}{l}{[+]} \\
{[-]} \\
{[+]} \\
{[+]} \\
{[+]}\end{array}$ & $\begin{array}{l}{[?]} \\
{[?]} \\
{[?]} \\
{[?]} \\
{[?]}\end{array}$ & $\begin{array}{l}{[+]} \\
{[-]} \\
{[?]} \\
{[+]} \\
{[+]}\end{array}$ & $\begin{array}{l}{[?]} \\
{[?]} \\
{[?]} \\
{[?]} \\
{[+]}\end{array}$ & $\begin{array}{l}{[+]} \\
{[?]} \\
{[+]} \\
{[+]} \\
{[?]}\end{array}$ \\
\hline Hand & $\begin{array}{c}\text { postaxial plydactyly } \\
\text { preaxial polydactyly } \\
\text { syndactyly }\end{array}$ & $\begin{array}{l}{[+]} \\
{[-]} \\
{[-]}\end{array}$ & $\begin{array}{l}{[+]} \\
{[?]} \\
{[?]}\end{array}$ & $\begin{array}{l}{[+]} \\
{[-]} \\
{[?]}\end{array}$ & $\begin{array}{l}+] \\
{[?]} \\
{[+]}\end{array}$ & $\begin{array}{l}{[+]} \\
{[?]} \\
{[?]}\end{array}$ & $\begin{array}{l}{[+]} \\
{[?]} \\
{[?]}\end{array}$ & $\begin{array}{l}{[+]} \\
{[-]} \\
{[?]}\end{array}$ & $\begin{array}{l}{[+]} \\
{[+]} \\
{[?]}\end{array}$ & $\begin{array}{l}{[+]} \\
{[-]} \\
{[-]}\end{array}$ & $\begin{array}{l}{[+]} \\
{[?]} \\
{[+]}\end{array}$ & $\begin{array}{l}{[+]} \\
{[+]} \\
{[+]}\end{array}$ \\
\hline Foot & $\begin{array}{c}\text { postaxial plydactyly } \\
\text { preaxial polydactyly } \\
\text { syndactyly } \\
\end{array}$ & $\begin{array}{l}{[+]} \\
{[-]} \\
{[+]}\end{array}$ & $\begin{array}{l}{[+]} \\
{[+]} \\
{[?]}\end{array}$ & $\begin{array}{l}{[+]} \\
{[+]} \\
{[+]}\end{array}$ & $\begin{array}{l}{[+]} \\
{[?]} \\
{[+]}\end{array}$ & $\begin{array}{l}?] \\
{[+]} \\
{[+]} \\
\end{array}$ & $\begin{array}{l}{[+]} \\
{[+]} \\
{[+]}\end{array}$ & $\begin{array}{l}+] \\
{[+]} \\
{[+]} \\
\end{array}$ & $\begin{array}{l}{[+]} \\
{[+]} \\
{[?]}\end{array}$ & $\begin{array}{l}{[-]} \\
{[+]} \\
{[?]}\end{array}$ & $\begin{array}{l}{[-]} \\
{[+]} \\
{[?]}\end{array}$ & $\begin{array}{l}{[+]} \\
{[+]} \\
{[+]}\end{array}$ \\
\hline CNS & & {$[-]$} & {$[+]$} & {$[+]$} & {$[+]$} & {$[+]$} & {$[+]$} & {$[+]$} & {$[-]$} & {$[+]$} & {$[+]$} & {$[+]$} \\
\hline Heart & & {$[+]$} & [?] & {$[+]$} & {$[+]$} & {$[+]$} & [?] & {$[+]$} & {$[+]$} & {$[-]$} & {$[-]$} & {$[+]$} \\
\hline Kidney & & {$[+]$} & {$[+]$} & {$[+]$} & {$[+]$} & {$[-]$} & [?] & [?] & {$[?]$} & {$[+]$} & {$[-]$} & [?] \\
\hline Other & \begin{tabular}{|c|} 
small thorax \\
lung/; breeding anomaly \\
Abnormal ribs \\
liver/biliary anomaly \\
genitalia? \\
short tibia \\
other
\end{tabular} & \begin{tabular}{|c|}
{$[+]$} \\
unilobulated \\
{$[?]$} \\
{$[+]$} \\
ambiguous \\
{$[+]$} \\
{$[-]$}
\end{tabular} & \begin{tabular}{|c|}
{$[+]$} \\
{$[+]$} \\
{$[+]$} \\
{$[+]$} \\
ambiguous \\
{$[+]$} \\
{$[?]$}
\end{tabular} & \begin{tabular}{|c|}
{$[+]$} \\
{$[-]$} \\
{$[?]$} \\
{$[+]$} \\
ambiguous \\
{$[+]$} \\
{$[?]$}
\end{tabular} & \begin{tabular}{|c|}
{$[-]$} \\
apnea \\
{$[-]$} \\
{$[?]$} \\
small penis \\
{$[+]$} \\
anal stenosis
\end{tabular} & \begin{tabular}{|c|}
{$[?]$} \\
apnea \\
{$[-]$} \\
{$[?]$} \\
{$[?]$} \\
{$[?]$} \\
{$[?]$}
\end{tabular} & $\begin{array}{c}{[?]} \\
\text { a/tachypnea } \\
{[?]} \\
{[?]} \\
\text { small penis } \\
{[?]} \\
{[?]}\end{array}$ & \begin{tabular}{|c|}
{$[?]$} \\
{$[+]$} \\
{$[-]$} \\
{$[+]$} \\
{$[?]$} \\
{$[?]$} \\
meningom
\end{tabular} & \begin{tabular}{|c|}
{$[?]$} \\
unibobulated \\
{$[?]$} \\
{$[?]$} \\
{$[?]$} \\
{$[?]$} \\
anterior-placed \\
anus \\
\end{tabular} & \begin{tabular}{|c|}
{$[?]$} \\
apnea \\
{$[-]$} \\
{$[?]$} \\
{$[?]$} \\
{$[?]$} \\
coloboma
\end{tabular} & \begin{tabular}{|c|}
{$[-]$} \\
{$[-]$} \\
{$[?]$} \\
{$[?]$} \\
agenesio penis \\
{$[?]$} \\
{$[?]$}
\end{tabular} & $\begin{array}{c}\text { tachypnea } \\
{[?]} \\
{[?]} \\
{[?]} \\
{[?]} \\
{[?]} \\
{[?]}\end{array}$ \\
\hline
\end{tabular}

Unilateral: asymmetric eye proptosis; unilobulated: one-lobe lung; meningom.: meningomyelocellae; colobma: optic split; agenesio: absent.

[16,19,28]. Ades et al. [29] reported a fetus with severe malformations of the kidneys, heart, hepatic ducts, lung and ambiguous genitalia. Cases of OFD with multiple skeletal and visceral involvement were also described [5,17,20,27,30-34]. Although there is heterogeneity between these reports, we suggest classifying all severe forms as a separate subgroup of OFD with multiple system involvement with mainly unfavorable outcome (Table 2).

Reports of cases with OFD syndromes show a wide variety of facial changes, from minor notches of the lip to complete oral clefts; from bifid tongue tip to lobulated and hamartomaus tongue; from hypoplastic nasal wings to bulbous or broad nose. These features may construct a specific pattern with variable appearance in different subgroups. The diagnosis of a specific OFD syndrome cannot be made only by the examination of the facial changes. However, some facial features, i.e., hypertelorism for types I, III and VI, broad nose for type II, alar hypoplasia and millia for type I, small teeth for type III, micrognathia for type IV, although not specific, may help clinical clarification between subtypes of OFD syndromes until a molecular diagnostic tool will be available.

\section{CONCLUSIONS}

We are contributing four new cases of OFD syndromes, each presenting a diagnostic and classification puzzle. It seems that the classification of OFD syndromes cannot keep adding new groups indefinitely. A molecular diagnostic tool is necessary to elucidate the pattern of anomalies in the syndrome. 


\section{REFERENCES}

1. Mohr OL. A hereditary subletal syndrome in man. Nor Vidensk Akad Oslo I mat Naturv Klasse. 1941; 14: 3-18.

2. Fenton OM, Watt-Smith SR. The spectrum of oralfacial-digital syndrome. Br J Plast Surg. 1985; 38(4): 532-539.

3. Toriello HV. Oral-facial-digital syndromes. Clin Dysmorphol. 1993; 2(2): 95-105.

4. Toriello HV. Are the oral-facial-digital syndromes ciliopathies? Am J Med Genet A. 2009; 149(5): 10891095.

5. Moran-Barroso V, Valdes Flores M, Garcia-Cavazos R, Kofman-Alfaro S, Saavedra-Ontiveros D. Oral-facial-digital (OFD) syndrome with associated features: a new syndrome or genetic heterogeneity and variability? Clin Dysmorphol. 1998; 7(1): 55-57.

6. Gabrielli O, Ficcadenti A, Fabrizzi G, Perri P, Mercuri A, Coppa GV, Giorgi P. Child with oral, facial, digital and skeletal anomalies and psychomotor delay: a new OFDS form? Am J Med Genet. 1994; 53(3): 290-293.

7. Degner D, Bleich S, Riegel A, Rüther E. [Orofacialdigital syndrome - a new variant? Psychiatric, neurologic and neuroradiological findings.] Fortschr Neurol Psychiatr. 1999; 67(12): 525-528.

8. Feather SA, Woolf AS, Donnai D, Malcolm S, Winter RM. The oral-facial-digital syndrome type 1 (OFD1), a cause of polycystic kidney disease and associated malformations, maps to Xp22.2-Xp22.3. Hum Molec Genet. 1997; 6(7): 1163-1167.

9. Thauvin-Rabinet C, Cossee M, Cormier-Daire V, Van Maldergem L, Toutain A, Alembik Y, Bieth E, Layet V, Parent P, David A, Goldenberg A, Mortier G, Heron D, Sagot P, Bouvier AM, Huet F, Cusin V, Donzel A, Devys D, Teyssier JR, Faivre L. Clinical, molecular, and geno-type-phenotype correlation studies from 25 cases of oral-facial-digital syndrome type 1: a French and Belgian collaborative study. J Med Genet. 2006; 43(1): 54-61.

10. Macca M, Franco B. The molecular basis of oralfacial-digital syndrome, type 1. Am J Med Genet C Semin Med Genet. 2009; 151C(4): 318-325.

11. Neri G, Gurrieri F, Genuardi M. Oral-facial-skeletal syndromes. Am J Med Genet. 1995; 59(3): 365-368.

12. Digilio MC, Marino B, Giannotti A, Dallapiccolla B. Orocardiodigital syndrome: an oral-facial-digital type II variant associated with atrioventricular canal. J Med Genet. 1996; 33(5): 416-418.

13. Verloes A. Numerical syndromology: a mathematical approach to the nosology of complex phenotypes. Am J Med Genet. 1995; 55(4): 433-43.

14. Fransceshini P, Guala A, Vardeu MP, Signorile F, Franceschini D, Bolgiani MP. Short-rib dysplsia group (with/without polydactyly): Report of a patient suggesting the existence of a continuous spectrum. Am J Med Genet. 1995; 59(3): 359-364.

15. Baraitser M. A female infant with features of Mohr and Majevski syndromes: variable expression, a genetic compound, or distinct entity? J Med Genet. 1983; 20(1): 65-67.

16. Camera G, Marasini M, Pozzolo S, Camera A. Oralfacial-digital syndrome: report on a transitional type between the Mohr and Varadi syndromes in a fetus. Am J Med Genet. 1994; 53(2): 196-198.

17. Chitayat D, Stalker HJ, Azouz EM. Autosomal recessive oral-facial-digital syndrome with resemblance to OFD types II, III, IV and VI: a new OFD syndrome? Am J Med Genet. 1992; 44(5): 567-572.

18. Levy EP, Fletcher BD, Fraser FC. Mohr syndrome with subclinical expression of the bifid great toe. Am J Dis Child. 1974; 128(4): 531-533.

19. Hsieh YC, Hou JW. Oral-facial-digital syndrome with Y-shaped fourth metacarpals and endocardial cushion defect. Am J Med Genet 1999; 86(3): 278-281.

20. Münke M, McDonald DM, Cronister A, Stewart JM, Gorlin RJ, Zackai EH. Oral-facial-digital syndrome type VI (Váradi syndrome): further clinical delineation. Am J Med Genet. 1990; 35(3): 360-369.

21. Al-Qattan MM, Hassanain JMA. Classification of limb anomalies in oral-facial-digital syndromes. J Hand Surg B. 1997; 22(2): 250-252.

22. Odent S, Le Marec B, Toutain A, David A, Vigneron J, Tréguier C, Jouan H, Milon J, Fryns JP, Verloes A. Central nervous system malformations and early endstage renal disease in oro-facio-digital syndrome type I: a review. Am J Med Genet. 1998; 75(4): 389-94.

23. Poretti A, Huisman TA, Scheer I, Boltshauser E. Joubert syndrome and related disorders: spectrum of neuroimaging findings in 75 patients. AJNR Am J Neuroradiol. 2011; 32(8): 1459-1463.

24. Hall JG, Pallister PD, Clarren SK, Beckwith JB, Wiglesworth FW, Fraser FC, Cho S, Benke PJ, Reed SD. Congenital hypothalamic hamartoblastoma, hypopituitarism, imperforate anus, and postaxial polydactyly - a new syndrome? Part I: clinical, causal, and pathogenetic considerations. Am J Med Genet. 1980; 7(1): 47-74.

25. Opitz JM, Penchaszadeh VB, Holt M C, Spano LM. Smith-Lemli-Opitz (RSH) syndrome bibliography. Am J Med Genet. 1987; 28(3): 745-750.

26. Verloes A, Ayme S, Gambarelli D, Gonzales M, Le Merrer M, Mulliez N, Philip N, Roume J. Holoprosencephaly-polydactyly ('pseudotrisomy 13') syndrome: a syndrome with features of hydrolethalus and Smith-Lemli-Opitz syndromes. A collaborative multicentre study. J Med Genet 1991; 28(5): 297-303

27. Toriello HV, Carey J, Suslak E, Desposito F, Leonard B, Lipson M, Friedman B, Hoyme E. Six pa- 
tients with oral-facial-digital syndorme IV: the case for heterogeneity. Am J Med Genet. 1997; 69(3): 250-260.

28. Annerén G, Gustavson KH, Jozwiak S, Kjartansson $\mathrm{S}$, Strömberg B. Abnormalities of the cerebellum in oro-facio-digital syndrome II (Mohr syndrome). Clin Genet (Copenhagen). 1990; 38(1): 69-73.

29. Ades LC, Clapton WK, Morphett A, Morris LL, Haan EA. Polydactyly, campomelia, ambiguous genitalia, cystic dysplastic kidneys, and cerebral malformation in a fetus of consanguineous parents: a new multiple malformation syndrome, or a severe form of oral-facial-digital syndrome type IV. Am J Med Genet. 1994; 49(2): 211-217.

30. Meinecke P, Hayek H. Orofaciodigital syndrome type IV (Mohr-Majewski syndrome) with severe expression expanding the known spectrum of anoma- lies. J Med Genet. 1990; 27(3): 200-202.

31. Toriello HV, Lemire E. Optic nerve coloboma, DandyWalker malformation, microglossia, tongue hamartomata, cleft palate and apneic spells: an existing oralfacial-digital syndrome or a new variant? Clin Dysmorphol. 2002; 11(1): 19-23.

32. Yildrim S, Akan M, Deviren A, Akoz T. Penile agenesis and clavicular anomaly in a child with oral facial digital syndrome. Clin Dysmorphol. 2002; 11(1): 29-32.

33. Balci S, Guler G, Kale G, Soylemezoglu F, Besim A. Mohr syndrome in two sisters: prenatal diagnosis in a 22-week-old fetus with post-mortem findings in both. Prenat Diag. 1999; 19(9): 827-831.

34. Iaccarino M, Lonardo F, Giugliano M, Della Bruna MD. Prenatal diagnosis of Mohr syndrome by ultrasonography. Prenat Diagn. 1985; 5(6): 415-418. 